\title{
The effect of cerium solutions on 316L stainless steel
}

\author{
M. Askarian ${ }^{1}$, M. Peikari ${ }^{2}$, S. Javadpour ${ }^{3}$, \\ S. Masoum ${ }^{1} \&$ A. Abolhasanzade ${ }^{2}$ \\ ${ }^{1}$ Pars Oil and Gas Company, Iran \\ ${ }^{2}$ Petroleum University of Technology, Iran \\ ${ }^{3}$ Shiraz University, Iran
}

\begin{abstract}
Surface passivation is a technique for improving the corrosion resistance of stainless steel. In this work, we studied the effect of cerium treatment on $316 \mathrm{~L}$ SS. Characterization techniques such as anodic polarization test, electrochemical impedance spectroscopy, and X-ray photoelectron spectroscopy were employed to correlate the corrosion behavior to surface treatments. Results showed that cerium passivation treatment increase corrosion protection of alloy due to the formation of amorphous oxidation that leads to diffusion control. This improvement is attributed to a more uniform and compact layer which is composed of oxide particles with higher oxygen and chromium concentrations. Keywords: passive layer, $316 \mathrm{~L}$ stainless steel, cerium, chemical treatment, electrochemical, SEM, XPS.
\end{abstract}

\section{Introduction}

Resistance of passive layer of stainless steel depends on the alloy composition and conditions in which it is generated. Chemical treatment on steel parts could improve passive layer [1]. Well-known method of surface modification involves the use of dichromate, a substance which is now recognized as both highly toxic and carcinogenic. The search for more environmentally acceptable alternatives has lead to the identification of rare-earth metal species as possible replacements for the chromium [6].

The anodic dissolution behavior of active-passive metals in the presence of oxidizers is illustrated in figure 1, which shows a typical active-passive metal $\mathrm{M}$ 
immersed in an electrolyte containing a redox agent $\mathrm{R}$. The effect of increasing the amount of oxidizer is to shift reversible potential in the positive direction according to the Nernst equation. The increase in oxidizing agent from concentration 1 to 7 is represented by curve 1 to 7 .

Initially, metal $\mathrm{M}$ corrodes in the active state at a rate corresponding to point A. as the concentration of oxidizer is increased from 1 to 3 , corrosion rate continuously increases from A to C. In this particular rang of oxidizer concentration, metal $\mathrm{M}$ acts like a nonpassivating metal; its corrosion rate increases with oxidizer concentration. At a concentration corresponding to the curve 4 , there is a rapid transition in corrosion potential from point $\mathrm{D}$ in the active state to $G$ in the passive state. As oxidizer concentration is increased from 4 to 5 , metal remains in the passive state and its corrosion rate remains low and constant. As the concentration of oxidizer is increased further, the transpassive region is intersected and corrosion rate increases rapidly with increasing oxidizer concentration, as shown by curve 6 and 7 in figure 1 .

This analysis leads to a very useful, practical rule. To safely maintain passivity, oxidizer concentration should be equal to or greater than the minimum amount necessary to produce spontaneous passivation.

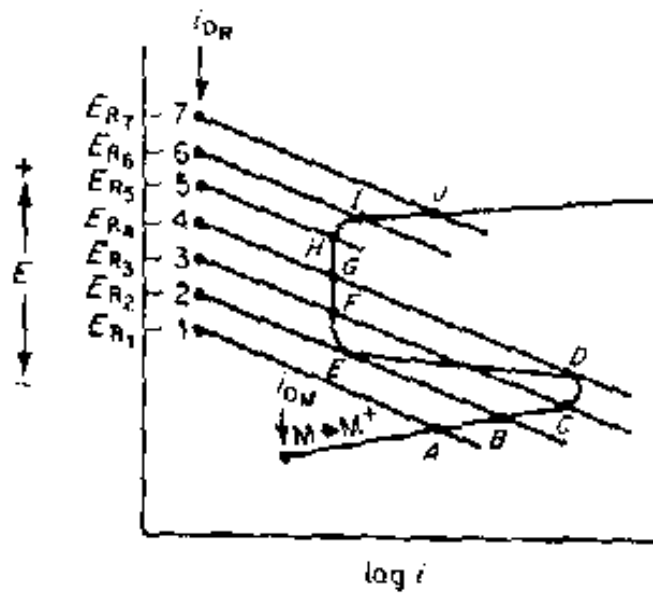

Figure 1: Effect of increasing oxidizing solution concentration on the electrochemical behavior of active-passive metal

The passive layer is formed by an oxidation-reduction reaction in which the chromium and iron are oxidized, and the passivating agent is reduced. An essential of the passivity of iron is the presence of $\mathrm{H}$ and $\mathrm{OH}$ groups which import the property of amorphousness, nonstoichimetry, and protectivity. The principal feature is the amorphousness and nonstoichiometry, leading to defect states associated with proton deficiency and a concentration gradient of the ionic species [21].

In this work, the behavior of 316L stainless steel following post cerium treatments was studied in an effort to examine the additional level of corrosion protection afforded by it. 


\section{Experimental}

Specimens used in this study were $316 \mathrm{~L}$ stainless steel. The composition in wt $\%$ was $0.021 \% \mathrm{C}, 17.61 \% \mathrm{Cr}, 12.45 \% \mathrm{Ni}, 2.29 \% \mathrm{Mo}, 0.069 \% \mathrm{Si}, 1.05 \% \mathrm{Mn}$, $0.020 \% \mathrm{~S}, 0.031 \% \mathrm{P}$, and bal. Fe. They were mounted with an exposed area to $1 \times 1 \mathrm{~cm}^{2}$. The surface was mechanically polished starting with 220 grit silicon carbide paper following 320 / 400 / 800 / 1000 grit paper to have a comparable surface roughness. They were then rinsed with deionized water.

Passivation treatments were conducted on specimens using immersion in $\mathrm{K}_{2} \mathrm{Cr}_{2} \mathrm{O}_{7}$ for 20 minutes at room temperature with $\mathrm{pH}=4$. The original specimen was studied as-received, without passivation treatment as reference and for comparative purposes.

Immediately after removal from the passivating solution the specimens were thoroughly rinsed, using spray washes [5].

The corrosion properties of the passive layer were studied using DC polarisation and electrochemical impedance spectroscopy (EIS). Electrochemical tests were conducted using Potentiostat, Model Zahner, in $3.5 \% \mathrm{NaCl}$ solution at room temperature opening air. Saturated calomel electrode (SCE) used as reference electrode and platinum used as auxiliary electrode. Potentiodynamic polarisation curves were plotted from $-200 \mathrm{mV}_{\mathrm{SCE}}$ to $+200 \mathrm{mV}_{\mathrm{SCE}}$ at a polarisation scan rate of $0.1 \mathrm{mV} / \mathrm{s}$; EIS measurements were performed in the frequency range from $100 \mathrm{mHz}$ to $100 \mathrm{kHz}$ with a logarithmic sweeping frequency of 4 steps/decade. EIS involved the imposition of a $10 \mathrm{mV}$ amplitude sine-wave and the measurements were carried out at the $\mathrm{E}_{\text {corr }}$.

Then the microstructure and composition of those specimens were investigated using X-ray photoelectron spectroscopy (XPS) to determine cause for this behavior. The XPS spectra were obtained with a VG Microtech electron spectrometer, model MT 500, using an $\mathrm{Mg} \mathrm{K} \alpha_{1.2}$ anode X-ray source (hv = $1253.6 \mathrm{eV}$ ) with a primary beam energy of $15 \mathrm{kV}$ and an electron current of $20 \mathrm{~mA}$. The pressure in the analysis cabinet was maintained at $1 \times 10^{-9}$ Torr throughout the measurements.

The specimens were analyzed by means of argon-ion sputtering on the original surface and after 30, 90, 200 and 390s argon-ion sputtering was carried out with primary beam energy of $5 \mathrm{kV}$ and an ion density of $1 \mu \mathrm{A} / \mathrm{cm}^{2}$.

\section{Results and discussion}

\subsection{Electrochemical tests}

Fig. 2 shows polarisation curves for specimens tested in a $3.5 \% \mathrm{NaCl}$ solution. To determine the corrosion rate from such polarization measurements, the tafel region is extrapolated to the corrosion potential and this point is corresponded to the corrosion rate of the system expressed in terms of current density. The $\mathrm{E}_{\text {corr }}$ and $\mathrm{I}_{\text {corr }}$ of each specimen are mentioned in table 1 [2].

As shown in fig. 2, electrochemical impedance spectra of an air passivated specimen (tested in a $3.5 \% \mathrm{NaCl}$ solution) in complex plane presentation are 
252 Computational Methods and Experiments in Materials Characterisation IV

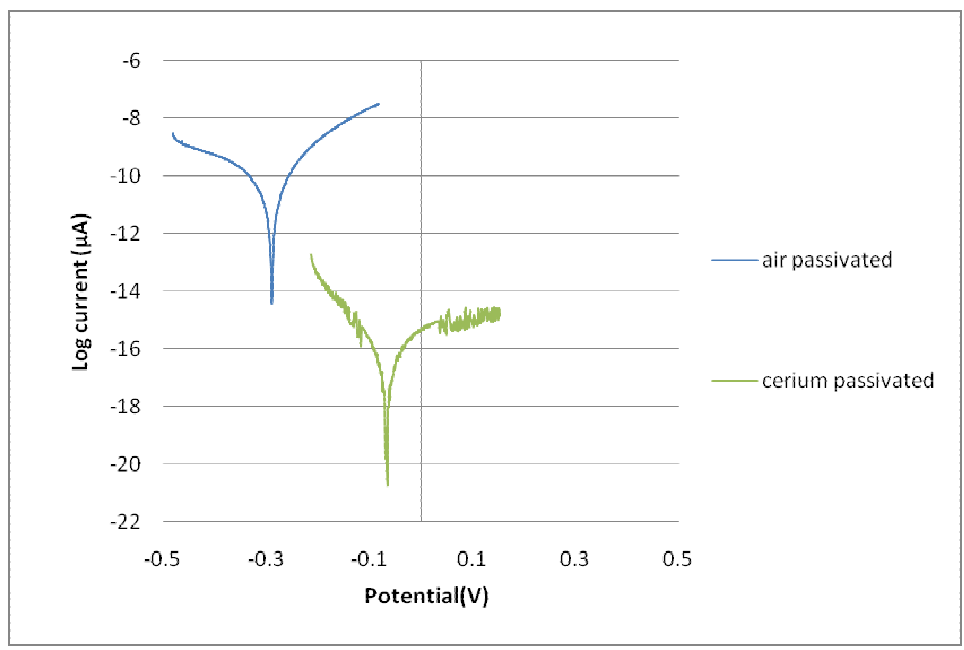

Figure 2: Polarization curve of specimen: (i) air passivated, (ii) cerium passivated.

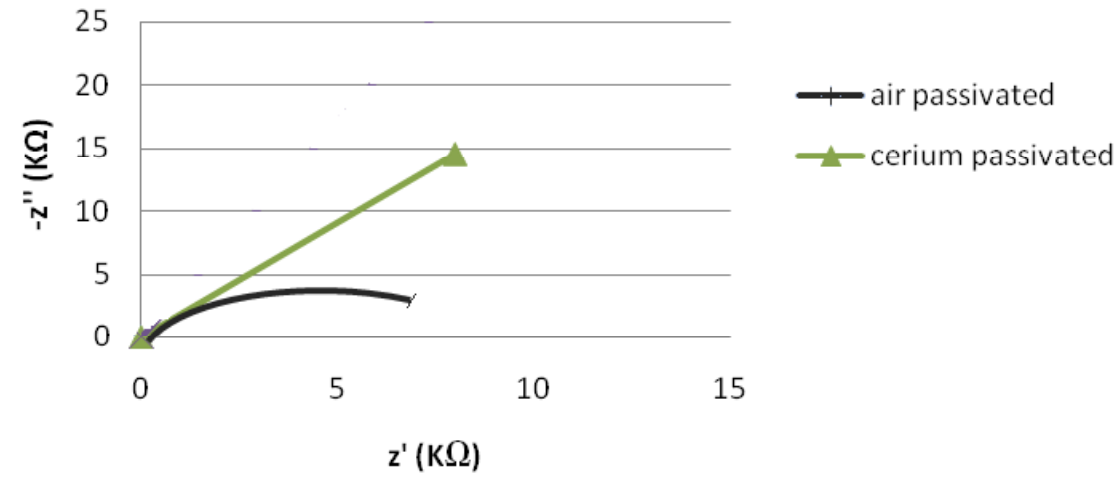

Figure 3: Nyquist plot of specimens: (i) air passivated, (ii) cerium passivated.

characterized by one semicircle, whereas spectra of cerium passivated specimen is straight line.

The quantitative analysis of the electrochemical impedance spectra must be based on a physical model of the corrosion process. Fig. 3 shows Randles Simple model includes the electrochemical resistance $\left(R_{p}\right)$ in parallel to the double layer capacitance (C) connected with the resistance of the electrolyte $\left(R_{s}\right)[8,9]$. Equation (1) represents a semicircle in the complex plane plot with $R_{p}$ as diameter:

$$
\left(Z^{\prime}-R_{S}-\frac{R_{P}}{2}\right)^{2}+\left(Z^{\prime \prime}\right)=\left(\frac{R_{P}}{2}\right)^{2}
$$


However, imagining impedances of cerium-passivated specimen showed it does not increase and capacitive semicircles are not completed. This behavior indicates the reaction is under diffusion control. Therefore the Warburg diffusion impedance is an inevitable element in circuit. Also capacitive is replaced with CPE (constant phase element) to fit with the experimental curve [8, 12]. The $\mathrm{CPE}$ behaviour could be treated as an " $\omega$ space fractality", i.e., as manifestation of a self-similarity in the frequency domain [27]. The CPE impedance is given by:

$$
Z_{C P E}=\frac{1}{(i w)^{n} A}
$$

where $\mathrm{A}$ is a proportionality coefficient and $\mathrm{n}$ has the meaning of the phase shift, which value can be considered as a measure of the surface inhomogeneity.

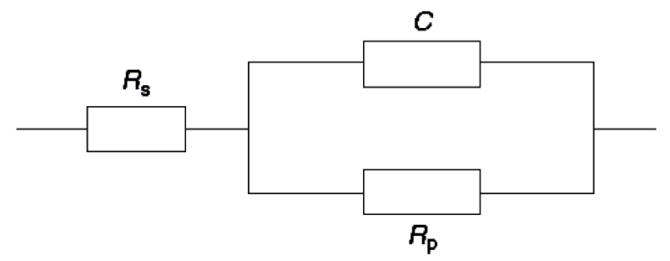

Figure 4: Randles Simple equivalent circuit of air passivated specimen.

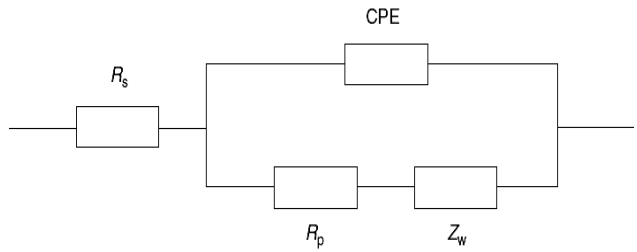

Figure 5: Equivalent circuit of cerium passivated specimen.

Table 1 indicates $R_{p}$ obtained from the equivalent circuit of each specimen. Electrochemical tests results show cerium treatment improves corrosion resistance of stainless steel.

Table 1: $\quad$ EIS and polarization tests results.

\begin{tabular}{|c|c|c|c|}
\hline sample & $\begin{array}{c}\text { Corrosion potential } \\
(\mathrm{mV})\end{array}$ & $\begin{array}{c}\text { Corrosion rate } \\
\left(\mathrm{nA} / \mathrm{cm}^{2}\right)\end{array}$ & $\begin{array}{c}\text { Resistance } \\
\left(\Omega / \mathrm{cm}^{2}\right)\end{array}$ \\
\hline Air passivated & -289 & 5100 & $1.2 \times 10^{3}$ \\
\hline Cerium passivated & -90 & 94 & $3.6 \times 10^{5}$ \\
\hline
\end{tabular}




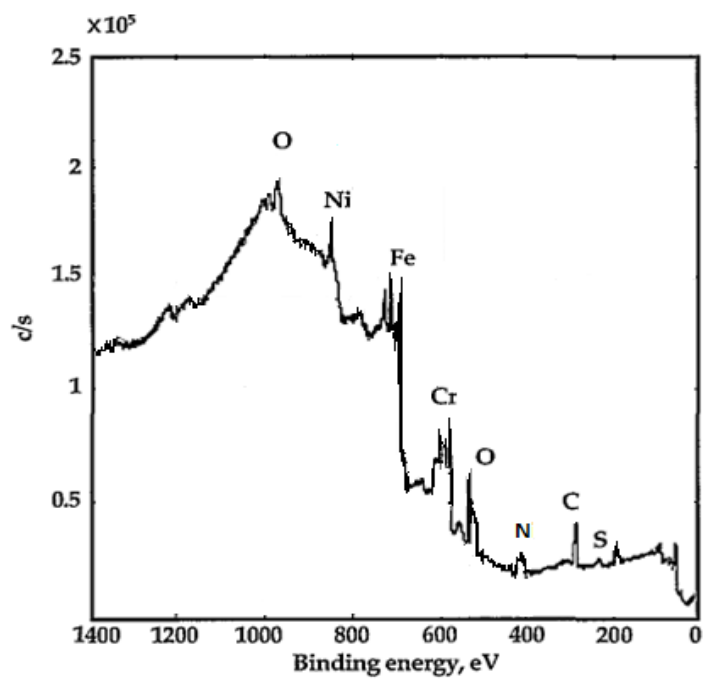

Figure 6: XPS spectra of air passivated specimen.

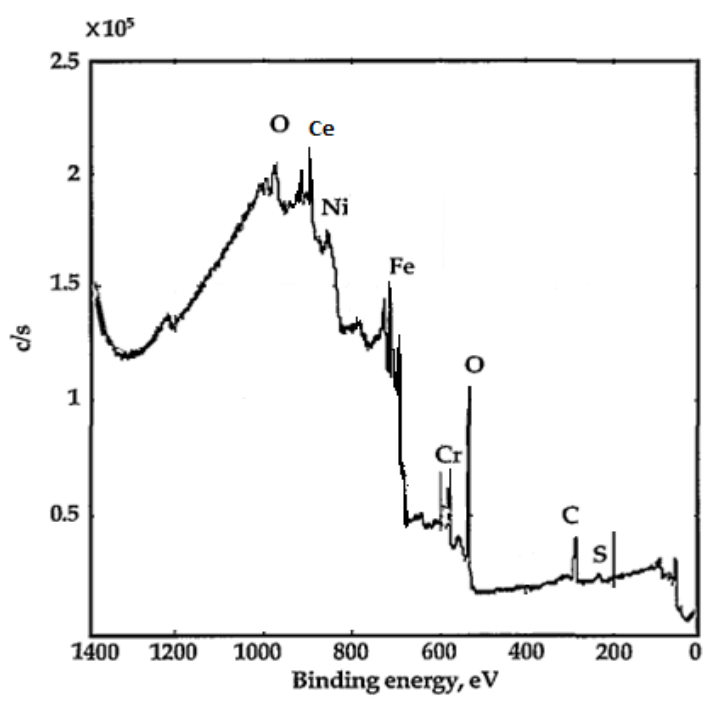

Figure 7: XPS spectra of cerium passivated specimen.

\subsection{XPS}

XPS analysis of stainless steel surfaces treated by various chemicals can provide valuable information about passivation layer composition.

The "surface atoms" are the atoms which would be in contact with the aqueous solution. A surface atom is drawn and is submitted to the possible events, surface diffusion, dissolution or passivation, according to probabilities 
dependent on the nature of the atom $(\mathrm{Cr}$ or $\mathrm{Fe})$ and on its chemical environment. The surface is then modified accordingly.

The XPS of spectrums of the passive film formed in air and cerium solution are shown in figures 6 and 7. It was found that there was the obvious Cr signal on the surface of cerium treated and slightly reduced $\mathrm{Cr}$ signal on the surface of the air-passivated [3].

The depth profile of the atomic concentration of each element can be obtained by high resolution XPS spectra at different argon-ion sputtering time. Figures 8 and 9 illustrate the concentration of oxygen, chromium, and iron in passive layer of $316 \mathrm{~L}$ stainless steel corresponding to air and cerium treatment.

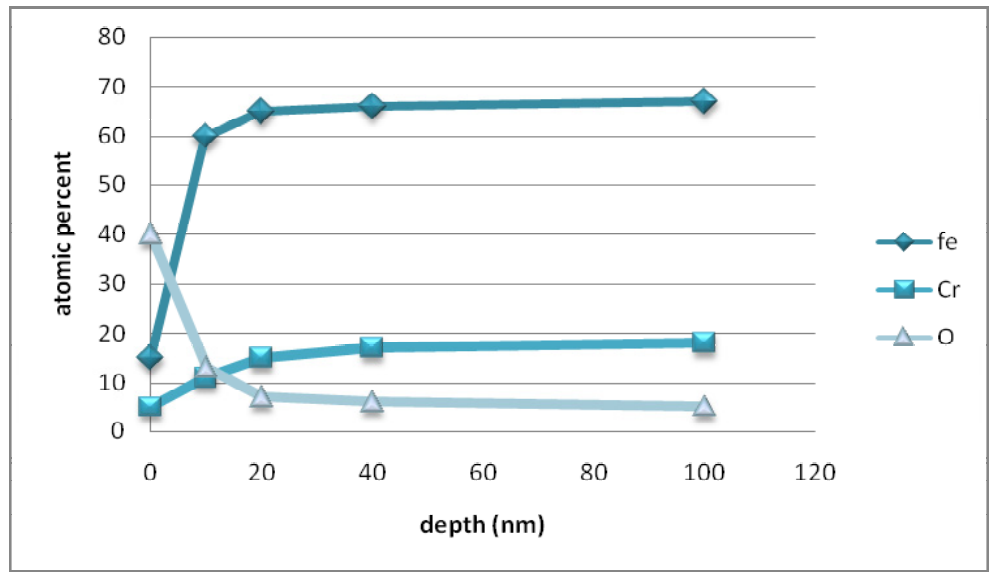

Figure 8: Atomic concentration of oxygen, chromium and ferrous elements for the Air-passivated specimen.

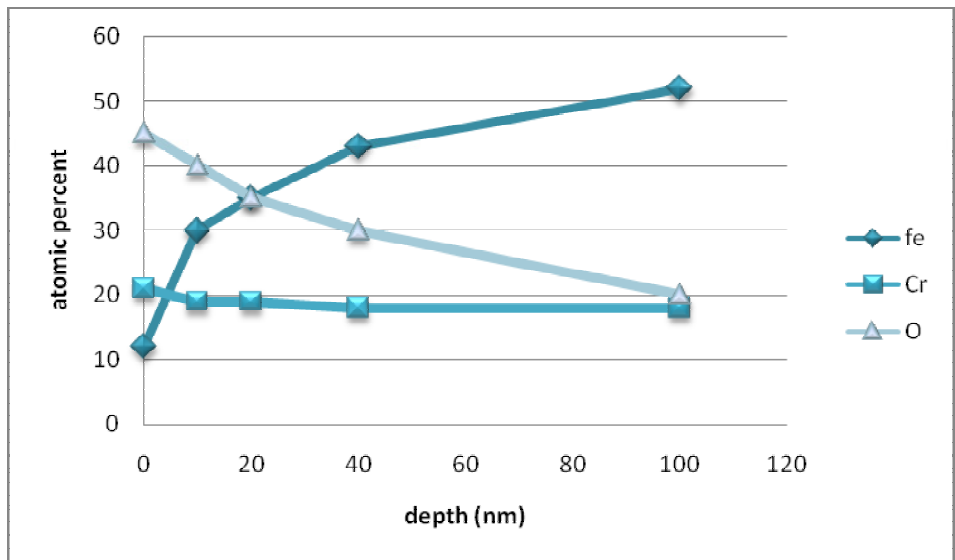

Figure 9: Atomic concentration of oxygen, chromium and ferrous elements for the cerium-passivated. 
Chromium is enriched in the surface of passive layer after chemical passivation. Corrosion resistance is the result of protection conferred by a chromium-rich passive layer.

Selective dissolution (of $\mathrm{Fe}$ ) and surface diffusion lead to the existence of oxide-hydroxide nuclei that will grow to finally cover the whole surface. In other words the passivation is due to formation of "oxide-hydroxide" nuclei, resulting from the presence of local chromium-rich clusters, the formation of which is favoured by selective dissolution of iron and by surface diffusion of chromium.

At the beginning, there is no nucleus on the initial surface. Therefore there is a strong selective dissolution. The surface becomes enriched in chromium, which can diffuse because vacancies have been created by the dissolution. Surface diffusion is necessary to fill up narrow channels that could be developed during dissolution. The surface roughness increases during this process. It also favours the formation of "chromium oxide" nuclei blocking the dissolution ("passivating the surface"), by preferential diffusion of $\mathrm{Cr}$ towards clusters of $\mathrm{Cr}$ atoms, whereas random diffusion of iron is considered. Small islands of chromium oxide are formed and grow during polarization in the passive region. After a certain time the local $\mathrm{Cr}$ concentrations become sufficient to form a number of nuclei. Then the passive layer grows rapidly because of the rapid $\mathrm{Cr}$ supply to the existing clusters. A significant amount of $\mathrm{Fe}$ is trapped in the passive film.

It suggests that surface diffusion of the chromium in the passive oxide layer is responsible for the chemical composition of passive films (chromium enrichment) in the early stages of passivation.

The chromate film has excellent corrosion protection, and the film is selfhealing. Scratches or gouges in the chromate film will reseal themselves upon contact with water or humidity.

Also cerium treatment promotes formation of $\mathrm{Ce}(\mathrm{OH})_{3}, \mathrm{CeO}_{2}$ and $\mathrm{Ce}(\mathrm{OH})_{4}$ which are amorphous $[3,10,11]$.

\section{Conclusion}

- The use of a rare earth metal salt, such as cerium nitrate, provides a degree of corrosion protection without incurring the health and environmental risks that are posed by chromates.

- DC measurements shows poor corrosion resistance behavior of air passivated specimen: $R_{p}=1.2 \mu \Omega \mathrm{cm}^{2}$ and $\mathrm{i}_{\text {corr }}=5.1 \mu \mathrm{A} / \mathrm{cm}^{2}$ respect to enhanced corrosion resistance behavior of cerium-passivated specimen: $R_{p}$ $=360 \mathrm{k} \Omega \mathrm{cm}^{2}$ and $\mathrm{i}_{\text {corr }}=0.094 \mu \mathrm{A} / \mathrm{cm}^{2}$

- $\quad$ EIS results indicated cerium passivation treatment lead to diffusion control by considering Warburg diffusion element in equivalent circuit.

- The XPS results indicated that chromium-passivation treatment was advanced in the $\mathrm{Cr}$ enrichment on the surface of stainless steel. 


\section{Acknowledgements}

Special thanks are directed to Dr. Kermaini. This paper was supported by Petroleum University of Technology (PUT), Pars Oil and Gas Company (POGC), and National Iranian Oil Company (NIOC).

\section{References}

[1] C.A.C. Sequeira, D.M.F. Santos, J.R. Sousa and P.S.D. Brito, The Mechanism of Oxide Film Formation on AISI 316 Stainless Steel in Sulphate Solution, 214th ECS Meeting, Corrosion General Poster Session, Honolulu, No. 1598

[2] Fontana, (chapter 10), Corrosion Engineering, McGraw-Hill Pub., New York, 1989

[3] Philippe Marcus, Florian Mansfeld, (eds). Analytical Methods in Corrosion Science and Engineering, CRC Press, Taylor \& Francis Group, 2006

[4] R. K. Gupta, (Chapter 10) Metal Surface Treatment And Their Chemicals, SBP Consultant and engineering PVT. Ltd, 2003

[5] ASM A967 Standard Specification for Chemical Passivation Treatments For Stainless Steel Parts, 2000

[6] M. Geary, C. B. Breslin, The Influence of Dichromate and Cerium Passivation Treatments on the Dissolution of Sn/Zn Coatings, Corrosion Science(39), pp. 1341-1350, 1997

[7] Tetsuo Fujii, Haruo Baba, The Effect of Oxidizing Ion on The Passivity, Corrosion Science (31), pp. 275-280, 1990

[8] Maryam Ehteshamzade (chapter 4), Application of EIS in corrosion study, Shahid Bahonar University Kerman p. , 2006

[9] SCK-CEN, Belgian Nuclear Research Centre, Boeretang Belgium, Electrochemical impedance spectroscopy for the detection of stress corrosion cracks in aqueous corrosion systems at ambient and high temperature" Corrosion Science (47), 125-143, 2005

[10] Y. Xingwen, C. Chunan, Y. Zhiming, Z. Derui, Y. Zhongda, Study of double layer rare earth metal conversion coating on aluminum alloy LY12, Corrosion. Science(43), 1283-1294, 2001

[11] X. Y. Wang, Y. S. Wu, L. Zhang, and Z. Y. Yu, Atomic Force Microscopy and X-Ray Photoelectron Spectroscopy Study on the Passive Film for Type 316L Stainless steel, Corrosion Science,(57)6, pg 540, 2001

[12] EG\&G Princeton Applied Research, Application Note Ac-1, Basic of ac Impedance Measurements, New Jersey, 1992

[13] John O'M. Bockris, Shahed U. M. Khan (chapter 8), Surface Electrochemistry, Springer, 1993 